\title{
Ectopic pancreatic tissue in a Gallbladder
}

\author{
Plinio Carlos Bau' ${ }^{1}$, Angelica Lucchese ${ }^{1 *}$, Fabio Barlem Hohmann², Vinicius \\ Duval Da Silva ${ }^{3}$, Josenel Maria Barcelos Marcal $^{3}$ \\ ${ }^{1}$ General and Digestive Surgeon, Sao Lucas Hospital of PUCRS, Porto Alegre, Brazil \\ ${ }^{2}$ General Surgeon, Sao Lucas Hospital of PUCRS, Porto Alegre, Brazil \\ ${ }^{3}$ Pathologist Sao Lucas Hospital of PUCRS, Porto Alegre, Brazil
}

Received: 27 August, 2016; Accepted: 10 November, 2016; Published: 21 November, 2016

*Corresponding author: Angelica Lucchese, General and Digestive Surgeon, Sao Lucas Hospital of PUCRS, Porto Alegre, Brazil; Phone Number: +555191631138; E- mail: angelca_luc@hotmail.com

\section{Abstract}

Ectopic or heterotopic pancreas is an abnormality of embryological origin and is defined as the presence of pancreatic tissue histologically identified outside the normal topography without any anatomical, vascular, or neural connection with the gland. Is a rare pathologic condition, but with the potential to cause severe symptoms sometimes attributed to idiopathic causes.

The authors present an asymptomatic patient who underwent laparoscopic cholecystectomy for polyps, and the pathology report describes the presence of associated pancreatic tissue. A brief review of the literature is also presented.

\section{Introduction}

Ectopic or heterotopic pancreas is an abnormality of embryological origin and is defined as the presence of pancreatic tissue histologically identified outside the normal topography without any anatomical, vascular, or neural connection with the gland [1-7]. Pancreatic heterotopia on the wall of the gallbladder is rare; Jean Schultz first described the condition in 1727, and Klob first confirmed its histopathology in 1859 [1, 6, 8].

The incidence of pancreatic heterotopia generally ranges from $0.55 \%$ to $13.7 \%$ in autopsy series and $0.2 \%$ in laparotomies $[1,4,8,9]$. Few cases have been reported regarding the presence of ectopic pancreas in the gallbladder, most of them being an incidental finding after cholecystectomy for cholecystitis [9]. The clinical significance of the presence of heterotopic pancreas in the gallbladder is unclear [5, 9].

The authors present an asymptomatic patient who underwent laparoscopic cholecystectomy for polyps, and the pathology report describes the presence of associated pancreatic tissue. A brief review of the literature is also presented.

\section{Case Report}

During a routine hospital check-up, a 57-year-old woman who was asymptomatic and had unremarkable past medical history underwent total abdominal ultrasonography. Results showed two polyps in the gallbladder, wherein the largest polyp measured $0.7 \times 0.5 \mathrm{~cm}$. Repeat ultrasonography after 6 months showed that polyp size increased to $1.0 \times 0.5 \mathrm{~cm}$, for which the patient underwent laparoscopic cholecystectomy. Family history showed that the patient's 80-year-old father and 54-year-old sister died of pancreatic and colon cancers, respectively. The pathology report described the presence of ectopic pancreas in the gallbladder wall [Figure 1] and polyp cholesterolosis.

\section{Discussion}

The presence of heterotopic pancreas has been described in the stomach, duodenum, jejunum, and spleen; it is rarely found in the ileum, liver, gallbladder, bile ducts, mesentery, lungs, mediastinum, and fallopian tubes [1, 3, 6-9]. Approximately $90 \%$ of the cases are located in the upper gastrointestinal tract [2]. The stomach is the most frequent site $(25-38 \%$ of cases), followed by the duodenum (30\%) and the jejunum (15\%). In the ileum, the heterotopic pancreas may be associated with Meckel's diverticulum, intestinal obstruction, or intussusception [4]. Only 33 cases of ectopic pancreas in the gallbladder have been described until 2013 [7].

A review of 212 cases of ectopic pancreatic tissue in the Mayo Clinic found only one instance in the gallbladder [6].

Heterotopic pancreas can be diagnosed at all ages, being more frequent in men; however, a higher incidence of heterotopic pancreas in the gallbladder is found in women [8]. This condition can occur in all age groups, but $50 \%$ of cases are diagnosed between the fourth and sixth decades of life $[4,6]$.

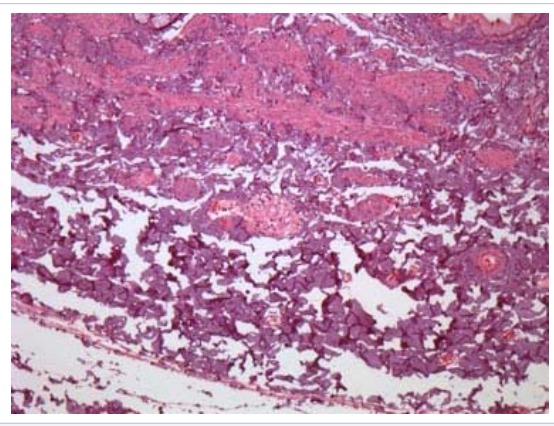

Figure 1: Single acinar structure beneath the muscular layer 
Histologically, the exocrine and endocrine components of the pancreas can be found in pancreatic heterotopic sites, including full differentiation of the islet in one-third of cases $[1,2,9]$.

The origin of heterotopic pancreatic tissue is controversial, and several theories have been proposed $[2,5,7,8]$. The most widely accepted theory is that the heterotopic pancreas is formed by a lateral bud of crude pancreatic duct during their penetration into the gut wall, and then carried by intestinal longitudinal growth $[7,8]$.

Although it is generally asymptomatic, heterotopic pancreas may become clinically evident when complicated by pathological alterations such as inflammation, hemorrhage, obstruction, and malignant transformation $[8,9]$

The most common clinical symptoms include epigastric pain (77\%), abdominal distension (30\%), melena (24\%), and vomiting (18\%) [9]. Symptomatic lesions generally have a size greater than $1.5 \mathrm{~cm}[9]$.

Moreover, the ectopic pancreatic tissue is associated with complications and changes that occur in the normal pancreas [3, $4,8]$. Patients presenting with acute pancreatitis in the normal pancreas tend to show an association with the inflammatory process in the heterotopic foci [4]. In contrast, the normal pancreatic tissue is usually not injured when local inflammation occurs in the heterotopic pancreas [4]. In cases of idiopathic acute pancreatitis, heterotopic pancreatic tissue should be considered as a differential diagnosis [7].

Patients with heterotopic pancreas may also present with clinical symptoms of peritonitis, cholecystitis [7]. Abdominal pain may be explained by inflammation of perilesional secondary tissue hormone and pancreatic enzyme secretion [9].

Soto et al. found high levels of amylase and lipase in bile, o pancreatic ectopic tissue present in the gallbladder. They proposed that exocrine activity might be associated with acute or chronic cholecystitis and the development of malignant lesions in the biliary tract [9].

Imaging studies used to evaluate the gallbladder, such as abdominal ultrasonography, computed tomography, and magnetic resonance imaging, usually cannot aid in the diagnosis of heterotopic pancreas in the gallbladder, and the diagnosis is usually made on the basis of the findings on histopathological analysis $[1,3,7]$.

These lesions are macroscopically firm and rounded, with a size ranging from a few millimeters to centimeters [8]. Fifty percent of heterotopic pancreatic tissue is found in the colon and gallbladder and can be located in the mucosa, muscularispropria, or serosa [8].

Microscopic examination can identify the presence of pancreatic tissue and classify it based on the Heinrich classification, as follows $[3,7,9]$ :
Type I: Pancreatic acini with tissue, ducts, islets, and pancreatic gland;

Type II: Canalicular variant pancreatic ducts;

Type III: Exocrine pancreas with acinar tissue;

Type IV: Endocrine pancreas with islet cells.

The treatment of choice is complete resection of the lesion [7, 9]. In most cases, surgery is the treatment of choice not only for the presence of symptoms, but also for purposes of diagnosis and exclusion of malignancies [9].

\section{Conclusion}

Heterotopic pancreas is a rare pathologic condition, but with the potential to cause severe symptoms sometimes attributed to idiopathic causes. Heterotopic pancreas must be considered in the differential diagnosis of lesions of the gallbladder wall without calculi such as polyps or nodules, especially if it coexists with amylasuria of unknown origin.

\section{References}

1. Kondi-Paphiti A, Antoniou AG, Kotsis T, Polimeneas G. Aberrant pancreas in the gallbladder wall. Eur Radiol. 1997;7(7):1064-1066. doi:10.1007/s003300050254.

2. Bahadir B, Ozdamar SO, Gun BD, Bektas S, Numanoglu KV, Kuzey GM. Ectopic pancreas associated with choledochal cyst and multiseptate gallbladder. Pediatr Dev Pathol. 2006;9(4):312-5.

3. Shiwani MH, Gosling J. Heterotopic pancreas of the gallbladder associated with chronic cholecystitis. JOP. 2008;9(1):30-2.

4. Zarand A, Bajtai A, Baranyai Z, Dede K, Jakab F. Inflammation of ectopic pancreatic tissue in a Meckel's diverticulum causing acute abdominal symptoms: a case report and review of the literature. Int J Surg Pathol. 2011;19(3):359-63. doi: 10.1177/1066896909331995.

5. Sato A, Hashimoto M, Sasaki K, Matsuda M, Watanabe G. Elevation of pancreatic enzymes in gallbladder bile associated with heterotopic pancreas. A case report and review of the literature. JOP. 2012;13(2):235-8.

6. Gonzalez Callejas C, Gonzalez Crespo F, Zurita Saavedra M, Cabrera Aguirre MA, Garcia Martos JB. Ectopic pancreas in the gallbladder. Cir Esp. 2013;91(2):130-1. doi: 10.1016/j.ciresp.2011.07.019.

7. Sroczynski M, Sebastian M, Hałon A, Rudnicki J, Sebastian A, Agrawal AK, et al. Pancreatic heterotopia in the gallbladder: an incidental finding after cholecystectomy. Folia Histochem Cytobiol. 2013;51(2):174-7. doi: 10.5603/FHC.2013.0025

8. Gucer H, Bagci P, Coskunoglu EZ, Karadag C. Heterotopic pancreatic tissue located in the gallbladder wall. A case report. JOP. 2011;12(2):152-4.

9. Sanchiz Cardenas EM, Soler Humanes R, Lavado Fernandez AI, Diaz Nieto R, Suarez Munoz MA. Ectopic pancreas in gallbladder. Clinical significance, diagnostic and therapeutic implications. Rev Esp Enferm Dig. 2015;107(11):701-3. doi: 10.17235/reed.2015.3627/2014. 